\title{
Do Disabled Candidates Represent Disabled Citizens?
}

\author{
Stefanie Reher \\ School of Government and Public Policy, University of Strathclyde, Glasgow, UK \\ E-mail: stefanie.reher@strath.ac.uk
}

(Received 27 January 2020; revised 28 July 2020; accepted 16 October 2020; first published online 10 February 2021)

\begin{abstract}
Whether citizens are better represented by politicians 'like them' has been the subject of much debate and analysis. Yet, this scholarship has largely ignored the 1 in 5 people who are disabled and experience economic, social and political marginalization. Linking voter and candidate data from the 2015 British general election, this study examines whether disabled citizens are better represented by disabled elites. It analyses the effects of disability on both preferences and preference congruence. The findings reveal that disabled citizens and candidates are more supportive of healthcare and general public spending, even within parties. At the same time, the views of disabled citizens are rarely more congruent with the positions of disabled candidates than those of non-disabled candidates, except on healthcare spending. The study provides ground-breaking insights into the role of disability in policy preferences and political representation while also highlighting broader implications of how the descriptive-substantive representation link is analysed.
\end{abstract}

Keywords: policy representation; preference congruence; disability; candidate survey; United Kingdom

An estimated 15 per cent of the world's population - over one billion people - live with a disability (WHO 2011). In the UK, 1 in 5 people report being disabled ${ }^{1}$ (DWP 2020). As the demographics of our societies change and more people live to an old age, this prevalence is likely to increase further (WHO 2011). According to Article 1 of the United Nations Convention on the Rights of Persons with Disabilities, disabled people 'have long-term physical, mental, intellectual or sensory impairments which in interaction with various barriers may hinder their full and effective participation in society on an equal basis with others' (UN General Assembly 2007). Being disabled has profound effects on many aspects of a person's life. Although they constitute a heterogeneous group - including, for instance, people with autism, limb amputations, longterm depression, multiple sclerosis and multiple impairments - disabled people share many of the same barriers and disadvantages, including social stigma and prejudice, higher poverty rates, a lower likelihood of being married and a greater risk of being the victim of a crime (Nario-Redmond 2020, 7).

Some legislation explicitly aims to address their concerns, for instance accessibility of transport and buildings, protection from discrimination, and disability allowances and benefits. But disabled people have also been shown to have distinct preferences beyond these specific 'disability issues', such as greater support for state involvement in the economy and more 'left-wing' views (Bernardi 2020; Gastil 2000; Lau and Heldman 2009; Mattila et al. 2017; Schur and

\footnotetext{
${ }^{1}$ The terminology around disability that is endorsed by the disability community varies across contexts. In the United States, 'people-first language' - i.e., a person with a disability- is used to emphasize that a person is not defined by their impairment. In the UK, on which this study focuses, the preferred term is disabled person to emphasize the idea of the social model that the barriers that exist in society disable a person (Oliver 1996).

( The Author(s), 2021. Published by Cambridge University Press. This is an Open Access article, distributed under the terms of the Creative Commons Attribution licence (http://creativecommons.org/licenses/by/4.0/), which permits unrestricted re-use, distribution, and reproduction in any medium, provided the original work is properly cited.
} 
Adya 2013). As such, one might argue that the interests of disabled people are best represented by people 'like them'. Indeed, the disability rights movement has been demanding political inclusion with the slogan 'Nothing About Us Without Us' since the 1990s (Charlton 1998).

While there may be various avenues to make their voices heard in the political process, the concept of descriptive representation (Pitkin 1967) focuses on the presence of members of a social group in parliament and government. The idea that this presence may improve the substantive representation of the group's interests in policy has engaged theorists (Mansbridge 1999; Phillips 1995) and empiricists alike for many decades. In this context, scholars have recently examined the similarities between the preferences of citizens and representatives from the same social groups, including women (for example, Boas and Smith 2019; Campbell et al. 2010; Clayton et al. 2019; Griffin, Newman and Wolbrecht 2012), ethnic and racial minorities (Boas and Smith 2019; Griffin and Newman 2007), social classes (Boas and Smith 2019; Wüest and Pontusson 2018), education strata (Schakel and Hakhverdian 2018) and religious groups (Boas and Smith 2019).

Yet political scientists have largely ignored the question of whether disabled politicians represent the views of disabled citizens. This may be due to the low numbers of politicians who openly identify as disabled and the difficulty of identifying people with hidden disabilities, as well as the low attention this group has received in the discipline. This study is the first to examine (1) whether disability affects the policy preferences of party candidates in a similar way to those of citizens and (2) whether the preferences of disabled candidates are more congruent with those of disabled citizens compared to those of non-disabled candidates. It uses rare survey data on disability and political attitudes among voters and candidates from the 2015 British general election.

The results show that disabled citizens in the United Kingdom are more ideologically left wing and more supportive of public spending, healthcare spending and income redistribution than non-disabled citizens, which is largely in line with findings from the United States (Gastil 2000; Schur and Adya 2013) and Finland (Mattila et al. 2017). The effects of disability on elite preferences are more mixed, however. While disabled candidates also show stronger support for healthcare and general public spending, they do not hold clearly distinct opinions on redistribution and are no more left wing than non-disabled candidates. This suggests that disabled candidates better represent the policy positions of disabled citizens on some, but not all, issues.

The analysis of the congruence between disabled citizens and candidates paints a somewhat different picture: the positions of disabled candidates are only rarely more proximate to those of disabled voters than those of non-disabled candidates. These results highlight that masselite similarities in preference gaps between social groups do not necessarily translate into closer preference congruence between the elites and citizens who belong to the group.

The study extends our knowledge of the role of disability in politics considerably, particularly at the level of political elites, where the impact of disability on preferences is revealed for the first time. The theoretical framework provides a rich foundation for further research into the factors that strengthen and weaken the role of disability in representatives' attitudes and behaviour. Importantly, despite the great diversity within the disability community, disabled citizens and candidates share distinct policy preferences. Thus the presence of disabled representatives has potentially positive implications for the substantive representation of the interests of disabled people in policy, and hence their everyday lives. As a result, it might also affect disabled people's orientations towards the political system. Furthermore, the study contributes to research on the descriptive-substantive representation link more generally. By illustrating how analyses of group-based preference gaps and congruence may lead to different conclusions, it encourages scholars in this field to carefully consider the assumptions and implications of their methodological strategies.

\section{The Link Between Descriptive and Substantive Representation}

Much of the recent scholarship on political representation relies on Hanna Pitkin's (1967) concepts and typology. Descriptive representation refers to the reflection of various characteristics of 
the represented among representatives, such as gender, social class, ethnicity or disability. Substantive representation occurs when representatives '[act] in the interests of the represented in a manner responsive to them' (Pitkin 1967, 209) and/or when policy output reflects citizens' preferences. The fact that parliaments and governments used to look vastly different from the wider society, and are still rarely an accurate reflection of it, has inspired scholars to ask whether the descriptive representation of a social group among power holders is conducive to, or even necessary for, the substantive representation of the group's interests in policy (Mansbridge 1999; Phillips 1995).

This question becomes relevant, and indeed answerable, only if the political views and interests of group members differ from those of non-members. If this condition is met, we can ask whether political representatives who belong to the social group are more likely to promote the group's preferences and interests (Campbell, Childs and Lovenduski 2010, 174). The small set of studies that have examined the role of disability in policy preferences, primarily in the United States, conclude that disabled citizens indeed have distinct policy preferences from non-disabled people (Gastil 2000; Lau and Heldman 2009; Schur and Adya 2013). This is remarkable given the group's diversity in terms of the nature, severity and origin of impairments as well as their cross-cutting characteristics and identities such as gender, age, ethnicity, education and religion. What unites them is that they all face barriers in various areas of private and public life, which can lead to distinct policy concerns as well as broader value orientations and political preferences.

Disabled people routinely experience inaccessible spaces, information and communication, as well as prejudice and the stigma of being dependent, incompetent and weak (Nario-Redmond 2010; Rohmer and Louvet 2018). These barriers significantly reduce their education, employment and income prospects (ONS, 2019a; ONS 2019b). Previous research tends to show that they have stronger support for state intervention in the economy, public spending and income redistribution (Gastil 2000; Lau and Heldman 2009; Schur and Adya 2013; see also Mattila et al. 2017, 107ff on the effects of health). These preferences might originate in a desire to improve their opportunities and living conditions, but potentially also in empathy with others who also find it 'difficult to be a model of rugged individualism and economic success' (Gastil 2000, 591). An issue of particular relevance from a self-interest perspective (cf. Huddy, Cassese and Lizotte 2008) is healthcare. Many - although, importantly, not all - disabled people require treatment or support provided by the (public) healthcare system for their impairments or conditions. In addition, they are more at risk of secondary health conditions and social determinants of poorer health (Emerson et al. 2012) and are often prevented from accessing healthcare services (McColl, Jarzynowska and Shortt 2010; Sakellariou and Rotarou 2017). And indeed, previous research shows that disabled people are more likely to support and prioritize public healthcare (Gastil 2000; Lau and Heldman 2009; Schur and Adya 2013).

Support for public spending, state intervention in the economy and income redistribution are traditionally associated with the left on the ideological spectrum. Findings from Finland confirm that the more 'restricted' people feel, the more left wing they tend to be (Mattila et al. 2017, 61-63). Gastil (2000) and Schur and Adya (2013) find that while disabled Americans do not identify as more liberal or left wing, they display more egalitarian beliefs and support for the Democrats than non-disabled people. In the UK and Europe, people with mental health conditions also identify more strongly with parties on the left (Bernardi 2020). In sum, we would expect disabled citizens to hold distinct political preferences from non-disabled citizens on a number of dimensions. With this necessary condition for the descriptive-substantive representation link met, the next question is whether these differences are likely to be mirrored by politicians.

\section{Disability and Politicians' Policy Preferences}

The relevant literature distinguishes between four mechanisms that may explain why representatives promote the interests and views of a social group they belong to: shared experiences, 
socialization, motivation to represent and electoral incentives (Boas and Smith 2019; Lloren, Rosset and Wüest 2015; Mansbridge 1999; Phillips 1995; Sobolewska, McKee and Campbell 2018). While this study does not empirically test the extent to which each of these mechanisms applies, they serve as a useful basis for discussing whether (and why) we would expect disabled politicians to display similar preferences as disabled citizens.

\section{Shared Experiences}

The most prominent mechanism thought to link descriptive and substantive representation is that of shared experiences giving rise to shared interests and a commitment to promoting them among political elites (Boas and Smith 2019; Lloren, Rosset and Wüest 2015; Mansbridge 1999; Phillips 1995). Disabled politicians are likely to have encountered similar physical, social, economic and legal barriers as other disabled people. Additional hurdles related to accessibility and perceptions in the political arena might further reinforce their disability identity and awareness. Some politicians are already involved in politics when they become disabled, especially since the prevalence increases with age. But this is also the case for citizens, and the extent to which attitudes and priorities may change as a result may be similar among citizens and elites. ${ }^{2}$

At the same time, it is possible that disabled political elites have different experiences from disabled citizens due to selection effects. Seeking election is a demanding undertaking for anyone, but disabled people face a distinct set of additional barriers (Evans and Reher 2020). Therefore, many of the disabled people who succeed in standing for office might have impairment types that imply fewer accessibility issues and less stigma compared to the 'average' disabled person in society. Moreover, disabled people standing as candidates might often have access to more financial resources, which may be necessary to pay for adjustments and support to 'level the playing field', such as transportation to campaign events or sign language interpreters. It is important to note that in the 2015 British election, disabled candidates could apply to the Access to Elected Office Fund to cover these costs. Yet, the fund was temporary and did not cover the earlier stages of the recruitment cycle, and it is unclear to what extent it allowed candidates to compete who would not have been able to otherwise. In sum, there are reasons both for and against the expectation that disabled candidates share the experiences of the wider disability community and, as a result, their policy positions.

\section{Socialization}

The socialization mechanism occurs when 'mutual influence among group members and their leaders [...] brings elite and mass opinion closer to one another over time' (Boas and Smith 2019, 312), mostly in groups with a high level of organization and a dense social network. Due to the great variety in the barriers faced by disabled people, horizontal interactions, but also top-down communication from movement and opinion leaders, are crucial for identifying shared political interests and formulating objectives. While disabled people are geographically dispersed and embedded in networks with non-disabled people, there are a range of settings that bring them together and offer opportunities for exchange, from schools to disabled people's organizations. The UK has a relatively dense population of such organizations, though with regional and local differences. While these groups are diverse in purpose, structure and membership, there is also a substantial degree of coordination (Inclusion London 2020). However, the extent to which political elites are involved in these networks is likely to vary greatly: while some may be very active, others might rarely interact closely and consciously with other disabled people and perhaps not even perceive themselves as part of a wider community. Therefore, socialization certainly has the potential to generate congruent preferences between disabled citizens

\footnotetext{
${ }^{2}$ Rapeli, Mattila and Papageorgiou (2020) provide evidence for a causal effect of negative (positive) changes in health on voting Labour (Conservative) in the UK.
} 
and political elites in the UK, but its impact is difficult to gauge without more information about individual candidates' involvement.

\section{Motivation to Represent}

Politicians often feel a responsibility to represent the social groups to which they belong, especially if they are under-represented and historically marginalized (cf. Mansbridge 1999; Sobolewska, McKee and Campbell 2018; Tremblay 2003). Some disabled politicians may have been motivated to enter politics precisely by a desire to act as a voice for the disability community. To the extent that they correctly identify the views of disabled citizens - including through shared experiences and socialization - this motivation should result in closer preference congruence. Yet, there are also reasons why disabled politicians might refrain from expressing views that make their disability salient, and instead hide or downplay their impairments. These factors include extrinsic pressures as well as intrinsic considerations.

Being perceived as a 'token' - meaning as one of few representatives of a group - often comes with high visibility and performance pressures, isolation and being stereotyped (Kanter 1977). In light of the persistent ableism in our societies, this might motivate disabled candidates to 'normalize' and deny their differentness (Nario-Redmond 2020, 345-46). Close scrutiny through parties, the media and political opponents (Durose et al. 2011) as well as rampant harassment and abuse targeted at politicians (Collignon and Rüdig 2020), combined with a rise in reported hate crimes against disabled people (Home Office 2019), might drive them to hide or downplay their disability. What is more, like all people, disabled politicians have a variety of identities and may seek to avoid 'role entrapment', where they are seen exclusively as spokespeople for disabled people and given political roles and responsibilities linked to this identity (Kanter 1977). Therefore, there are powerful arguments both in support of and against the notion that disabled politicians will be motivated to represent the views of disabled citizens.

\section{Electoral Incentives}

Finally, the incentives created by the institutional, and specifically the electoral, context are likely to shape candidates' expressed preferences and behaviour. In first-past-the-post (FPTP) systems like the UK, where candidates need to win a plurality of votes to get elected, appealing to a minority group may not be a viable strategy. Unlike groups that are sometimes geographically concentrated, such as some ethnic minorities (Sobolewska, McKee and Campbell 2018), disabled people generally do not constitute a majority in any electoral district. Therefore, disabled candidates have an incentive to adopt policy positions and priorities that appeal to a broader constituency of voters when seeking the support of the party selectorate and in the election itself (Norris and Lovenduski 1995). This is different in proportional representation (PR) systems, where each district has a group of representatives, 'the members of which may represent the different interests that exist' (Tremblay 2003, 221). Indeed, there is evidence that representatives elected via FPTP are less likely to see themselves as representatives of their social group than those elected via PR (Coffé 2018; Crisp et al. 2016; Tremblay 2003).

At the same time, we know that many voters want politics to better reflect the diverse make-up of society, which has prompted the main parties in the UK to take steps to nominate more women and ethnic minority candidates (Cowley 2013; Sobolewska 2013). In the same vein, disabled candidates may have felt encouraged to draw on their identity and lived experience when developing their policy platforms. To conclude, with respect to all four mechanisms discussed here, there are strong arguments both in favour of and against the expectation that disabled representatives will reflect the policy preferences of disabled citizens where they are distinct from the positions of non-disabled citizens. This provides a strong motivation to empirically study the role of disability in mass-elite congruence, even if the available data do not yet allow us to examine the roles of the different mechanisms. 


\section{Data and Method}

Data that allow us to examine the relationship between disability and policy preferences are scarce, especially for political elites. Fortunately, the Parliamentary Candidates UK Dataset from the 2015 Representative Audit of Britain (van Heerde-Hudson and Campbell 2015) included a question on disability. 1,193 candidates from the major parties responded to the survey, who constitute 30 per cent of the candidates who stood for election in 2015 (37 per cent of the major party candidates) and 19 per cent of the elected Members of Parliament (MPs) (10 per cent of candidates in the survey were elected to the House of Commons in 2015, compared to 16 per cent of all candidates) (Keen 2015). Among these candidates, 688 responded to the disability question in the survey. These candidate data are linked with citizen data from Wave 6 of the British Election Study Internet Panel (Fieldhouse et al. 2015), which was collected shortly after the 7 May 2015 election. The analysis is based on the 'core sample' of 20,023 respondents, which is representative of the UK public. ${ }^{3}$

\section{Disability Measures}

The survey asked candidates 'Do you consider yourself to have a disability?', while voters were asked 'Do you have any long-term illness, health problem or disability which limits your daily activities or the work you can do?' While the questions are not identical, they are both inclusive and rely on respondents' self-identification. Both variables were recoded into binary indicators, excluding those who did not provide an answer. A total of 24.4 per cent of voters indicated that they were disabled, in comparison to only 11 per cent of candidates, or 10.3 per cent when weighted to reflect the number of candidates fielded by each party in the election. This suggests that disabled people are descriptively under-represented in UK politics, which is valuable information in itself, given that statistics on disability among candidates and politicians are extremely scarce. Table 1 shows the figures for candidates identifying as disabled in each of the political parties. The proportions vary between 8 and 13 per cent for all parties except for the Conservatives and Plaid Cymru, where no candidates indicated a disability. ${ }^{4}$

\section{Preference Gaps and Congruence: Two Ways of Measuring Substantive Representation}

I use two distinct approaches to answering the question of whether disabled candidates reflect the policy preferences of disabled citizens better than non-disabled candidates. First, I analyse whether being disabled affects the policy preferences of voters and candidates in similar ways. In other words, are the disability gaps in citizen preferences mirrored among candidates? I estimate the effects of disability on policy positions among the voter and candidate samples, respectively, as follows:

$$
\text { Position }_{i, d}=\beta_{0}+\beta_{1} \text { Disability }_{i}+\beta_{2-10} \text { Controls }_{i}+\epsilon_{i}
$$

and

$$
\text { Position }_{j, d}=\beta_{0}+\beta_{1} \text { Disability }_{i}+\beta_{2-10} \text { Controls }_{j}+\epsilon_{j}
$$

with $i$ indexing voters, $j$ indexing candidates, and $d$ indexing the policy dimensions. I investigate a set of four dimensions on which we might expect disability gaps, as explained in the discussion above: (1) left-right ideology; (2) cuts to public spending; (3) cuts to National Health Service (NHS) spending and (4) income redistribution. Appendix Table S1 provides detailed information

\footnotetext{
${ }^{3}$ Note that these samples are reduced in the analyses due to missing values for different variables.

${ }^{4}$ It is widely known that the Conservatives did nominate disabled candidates, meaning that either the sample does not include them or they chose not to disclose their disabilities.
} 
Table 1. Disabled candidates in the sample by party

\begin{tabular}{lll}
\hline & \multicolumn{1}{c}{$\begin{array}{c}\text { N of disabled/total N of } \\
\text { respondents }\end{array}$} & Percentage of candidates who report a disability \\
(\%)
\end{tabular}

Note: total number of respondents only includes those who gave a valid response to the disability question.

about these measures. All scales are normalized to range from 0 to 1 and coded so that higher values indicate more right-wing attitudes (that is, opposition to spending and redistribution).

I estimate these models both with and without controls for candidates' and voters' party affiliation. For voters, this is measured as their vote choice in the 2015 election; citizens who did not vote are not included in the analysis. By providing information about the positions and (future) behaviour of their representatives, political parties are key facilitators of the political representation of public preferences. Voters (and candidates) can select the parties that best match their preferences, which may be shaped by being disabled alongside a range of other factors. It is possible that through this process party affiliation 'absorbs' any disability gaps in citizens' policy preferences. If no disability effects exist within parties, one might conclude that disabled voters will not benefit from having disabled politicians in order for their preferences to be represented on the respective policy dimension. The opposite would be the case if disability gaps exist even within parties. ${ }^{5}$ Analysing the within-party effects of disability, in addition to the effects across parties, is thus a more conservative or demanding test of the descriptive-substantive representation link.

The second approach to analysing the descriptive-substantive representation link asks whether disability affects voter-candidate preference congruence. In other words, are the policy positions of disabled citizens more proximate to those of disabled candidates than those of non-disabled candidates? Focusing only on representation within parties, I construct separate datasets for each party where the unit of analysis is a voter-candidate dyad. This approach has been used by Boas and Smith (2019) and Lupu and Warner $(2017,2020)$ to analyse mass-elite preference congruence and by Wüest and Pontusson (2018) to investigate whether voters of a particular social class are better represented by elites from that class. It allows us to analyse whether shared disability increases preference congruence between each voter and each candidate - that is, many-to-many congruence (Golder and Stramski 2010). In contrast to approaches that compare the distributions of groups of voters to those of elites (Dingler, Kroeber and Fortin-Rittberger 2019; Golder and Stramski 2010; Schakel and Hakhverdian 2018), this method allows us to control for other characteristics of voters and candidates.

I measure congruence on each of the four dimensions as the absolute difference between voter $i$ and candidate $j$ who are linked by the dyad, both affiliated with party $p$, subtracted from 1 so that higher values indicate closer congruence:

$$
\text { Congruence }_{(i j), p, d}=1-\mid \text { position }_{i, p, d}-\text { position }_{j, p, d} \mid
$$

\footnotetext{
${ }^{5}$ Studies of the descriptive-substantive representation link in the context of gender have addressed this issue (see also Mansbridge's (1999) discussion of uncrystallized interests). Parties have sometimes been found to absorb differences in representatives' positions, although most studies show that opinion gaps between women and men persist within parties (cf. e.g. Campbell et al. 2010; Griffin et al. 2012; Lovenduski and Norris 2003; Wängnerud 2000).
} 
(a) Same disability effect, closer $\mathrm{d} / \mathrm{d}$ congruence

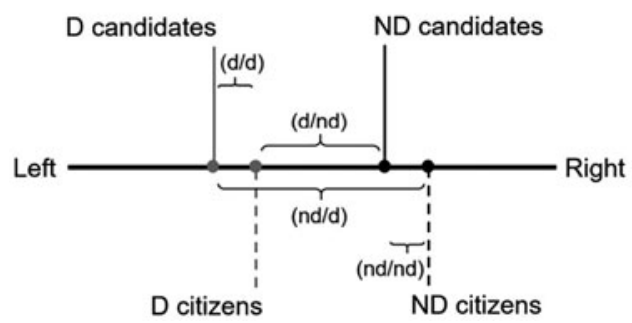

(b) Same disability effect, no closer d/d congruence

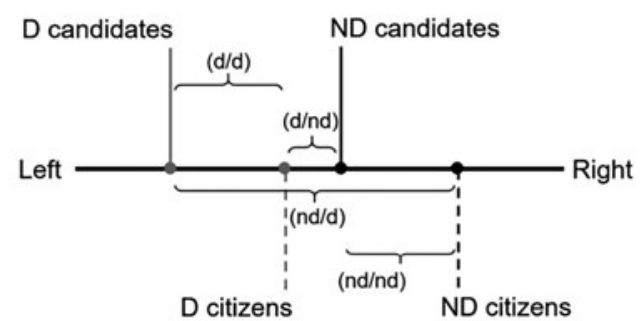

Figure 1. Illustration of hypothetical mean positions of citizens and candidates on the left-right dimension Note: $\mathrm{d}$ = disabled, $\mathrm{nd}=$ non-disabled.

Again, the scales are normalized to range from 0 to 1 . I then estimate the following linear models separately for each party and policy dimension, where $x^{T}{ }_{(i, j), p}$ is a vector of dummy variables indicating three of the four combinations of candidate and voter disability:

$$
\text { Congruence }_{(i j), p, d}=\beta_{0}+\beta_{1-3} x_{(i j), p}^{T}+\beta_{4-5} \operatorname{Controls}_{(i j), p}+\epsilon_{(i j), p}
$$

The two ways of measuring substantive representation - (1) similarity in the effects of disability on the policy preferences of elites and citizens and (2) the effect of disability on citizen-elite congruence - have distinct underlying concepts and will not necessarily yield the same conclusions. The main reason is that citizens and elites are not necessarily located in the same positions on the preference scales (for example, Belchior 2010; Golder and Stramski 2010). To illustrate this, Figure 1 shows two scenarios. In both, the disability gaps in the average left-right positions of candidates and citizens have the same direction and magnitude. Yet the congruence patterns clearly differ. In Scenario A, the average disabled citizen is closer to the average disabled candidate than the non-disabled candidate. In Scenario B, the disabled citizen is more proximate to the non-disabled candidate, because the candidates are generally more left wing than the citizens. ${ }^{6}$

Both of these measures embody key aspects of the descriptive-substantive representation link. Preference congruence could be considered a direct translation of the concept of substantive representation: politicians whose views are more similar to those of a group of citizens should be more likely to promote the policy positions of that group. Congruence measures are prominent in research on the representation of social groups such as women, the poor or ethnic minorities (for example, Dingler, Kroeber and Fortin-Rittberger 2019; Giger, Rosset and Bernauer 2012; Griffin and Newman 2007) and on policy representation more generally (for example, Golder and Stramski 2010; Huber and Powell 1994). Yet, as we saw in the example above, by only analysing congruence we might miss parallels in the impact of disability on the opinions of both citizens and elites. Systematic disability preference gaps might be both a result and a driver of awareness among elites of how being disabled shapes people's policy interests and political opinions. As a result, disabled politicians might be more likely to advocate for the distinct interests of disabled people, independently of the congruence level. The preference gap approach has been used, for instance, by Campbell, Childs and Lovenduski (2010) to study whether women are better represented by women.

\footnotetext{
${ }^{6}$ For the sake of simplicity, I illustrate the mean citizen and candidate positions here, although the congruence measure links each individual citizen and candidate rather than their average positions. The distributions and mean positions of citizens and candidates for the four preference dimensions based on the data are shown in Appendix Figure S1.
} 


\section{Control Variables}

Disability is situated early in the hypothesized causal chain explaining ideology and policy preferences. It is likely to affect a range of views, experiences and resources that in turn affect policy preferences, but is unlikely to be influenced by most of them. Therefore, the models include only two control variables in addition to party. I control for gender (female or male) in the analysis of the disability effect on preferences, and the shared gender of voter and candidate in the analysis of congruence. Women are more likely to be disabled than men (ONS 2019b) and to have different policy preferences on a range of issues. I also control for age in the analyses of disability preference gaps, and for the age difference between voter and candidate in the analysis of congruence. This is important because the probability of being disabled increases sharply as people get older (ONS 2019b). In the data used here, age is indeed strongly related to disability among citizens but, interestingly, not among candidates. Female citizens in the sample are marginally more likely to be disabled, while there is no such difference among candidates (Table S2).

\section{Results}

\section{Effects of Disability on Policy Preferences}

I examine whether disability affects the policy preferences of citizens and candidates by estimating linear regression models with each of the four preference scales as dependent variables and disability and the control variables as predictors. The candidate data are weighted to reflect the number of candidates who stood for each party across the UK. The coefficients of disability from these models are shown in Figure 2 (see Appendix Tables S3 and S4 for full estimates). Across parties, disabled voters place themselves 0.05 points to the left of non-disabled voters on a scale from 0 to 1. This gap disappears when party affiliation is added to the model, meaning that once voters have sorted themselves into parties, the ideological positions of disabled and non-disabled voters do not differ. Remarkably, candidates' disabilities do not appear to affect their left-right positions at all, neither across nor within parties.

By contrast, both disabled citizens and candidates are more supportive of public spending than their non-disabled counterparts. Among citizens, the disability gap of 0.09 points on the $0-1$ scale across parties shrinks to 0.04 points within parties but remains statistically significant. For comparison, the gender preference gap is 0.05 points across parties and 0.04 within parties, with women showing stronger support for public spending (see Table S3). Among candidates, the disability gap is 0.08 points across and 0.06 points within parties, although the latter is not statistically significant $(p=0.06)$. However, given that the number of disabled candidates in the sample is fairly small, we can still consider this finding as a likely indication of parallel preference gaps among citizens and elites both across and within parties.

The patterns look similar for voter preferences regarding spending on the NHS: both across and within parties, disabled voters are more strongly opposed to spending cuts. The disability effects on candidates' preferences are even larger than on public spending: across parties, disabled candidates are more supportive of healthcare spending than non-disabled candidates by onetenth of the scale, which decreases only slightly when holding their party constant. Finally, disabled voters in the UK are clearly more supportive of income redistribution both across ( 0.1 points) and within parties ( 0.06 points). We see a similar tendency among candidates, but these disability gaps are not statistically significant. ${ }^{7}$

Overall, these findings suggest that disabled politicians might indeed be better representatives of disabled citizens than non-disabled politicians with regard to some key policy issues, namely healthcare spending as well as public spending in general. It is also noteworthy that most of the

\footnotetext{
${ }^{7}$ Appendix Figure S2 shows the results of equivalent models that also control for education and income. All disability effects shown in Figure 1 are robust to holding education and income constant, except for the effect on public spending attitudes among candidates.
} 
(a) Left-right position

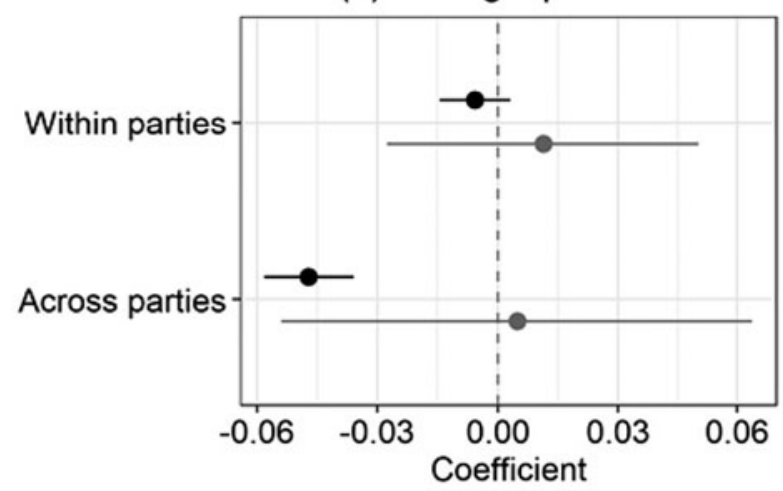

(c) NHS spending

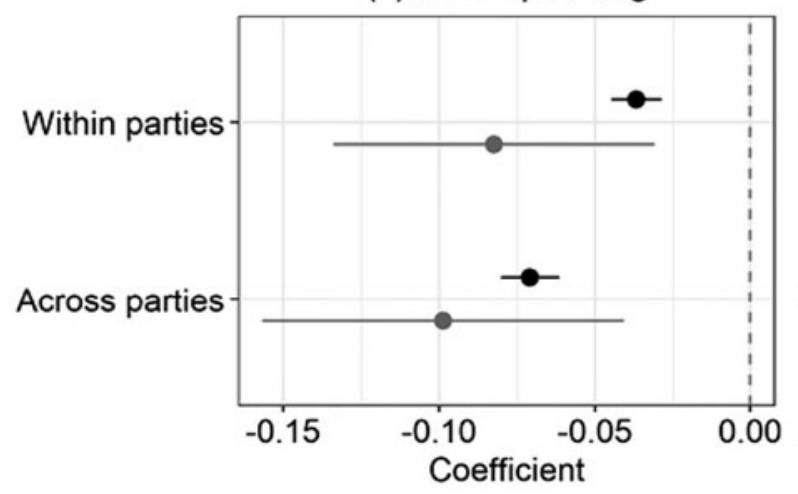

(b) Public spending

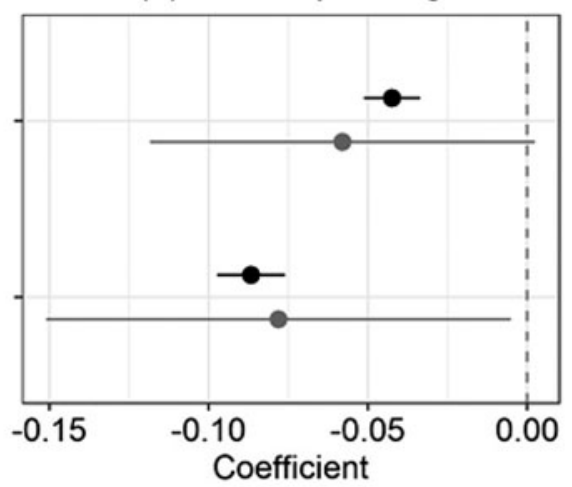

(d) Redistribution

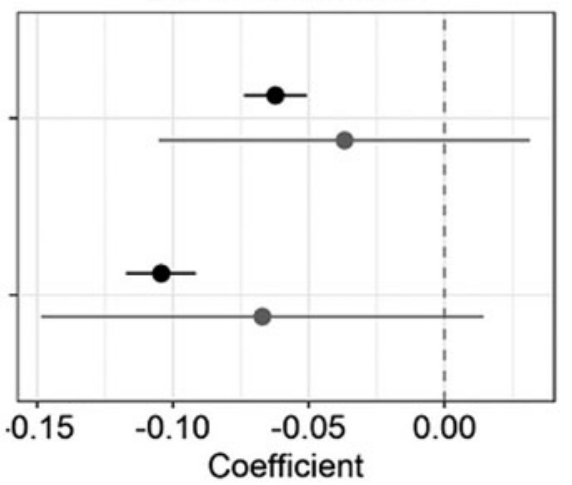

\section{Q Citizens $\phi$ Candidates}

Figure 2. Effects of disability on policy preferences of citizens and candidates

Note: values are coefficients of disability and 95 per cent $\mathrm{Cls}$ from linear regression models among citizens and candidates. Estimates are provided in Appendix Tables S3 and S4. 'Across parties' models include disability, gender, age. 'Within parties' models include disability, gender, age, party.

disability preference gaps among both candidates and citizens exist not only across political parties but remain significant when controlling for party affiliation, which suggests that the interests of disabled people have not been fully integrated into party politics.

\section{Effects of Shared Disability on Dyadic Preference Congruence}

To examine whether shared disability increases preference congruence between citizens and elites, I analyse the voter-candidate dyads by regressing the preference congruence measure on binary indicators for each combination of disabled and non-disabled citizens and candidates. The models control for shared gender and the age difference, and include random intercepts at the levels of both citizens and candidates. Only parties that have more than ten candidates identifying as disabled in the sample are included in these analyses: Labour, the Liberal Democrats, the Green Party (including the Scottish Greens) and the UK Independence Party (UKIP).

Figure 3 shows the coefficients of shared disability on citizen-candidate congruence for each party and policy dimension (for the full results, see Appendix Tables S5 and S6). The coefficients indicate how congruent the preferences of the respective citizen group are with the preferences of 

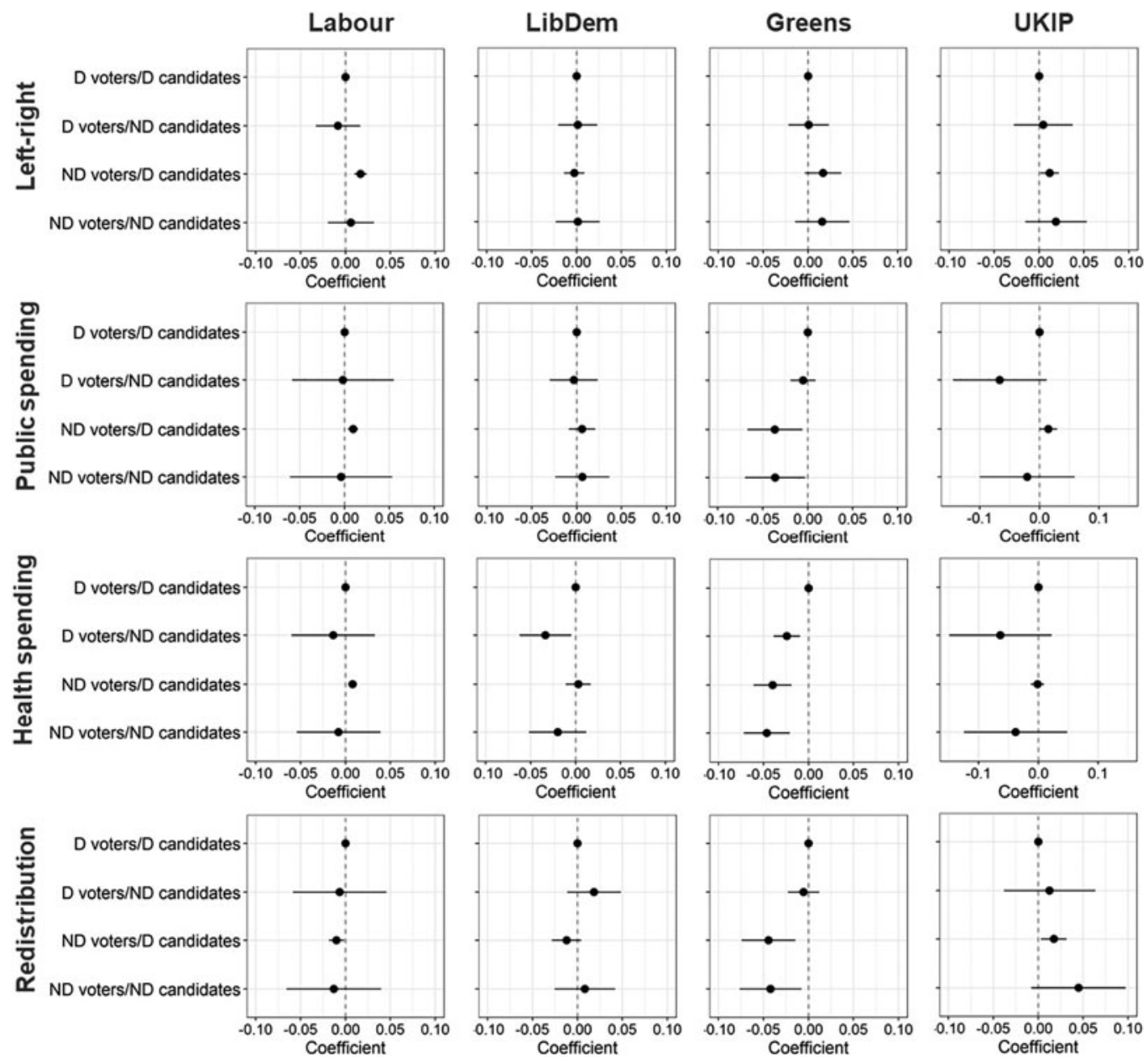

Figure 3. Estimates preference congruence based on voter and candidate disability

Note: values are coefficients (with 95 per cent Cls) of binary variables indicating combinations of disabled (D) and non-disabled (ND) citizens and candidates from linear regression models estimated on voter-candidate dyads, controlling for shared gender and age difference and including voter and candidate random intercepts. The full estimates are provided in Appendix Tables S5 and S6.

the respective candidate group as compared to dyads of disabled voters and candidates, which are the reference category. Our focus is on the second coefficient from the top in each plot, which tells us how congruent disabled citizens are with non-disabled candidates compared to disabled candidates. If this coefficient is negative, disabled citizens' preferences are closer to those of disabled than those of non-disabled candidates.

In none of the parties are disabled citizens closer to disabled than non-disabled candidates on the left-right dimension. This is in line with our prior finding that there are no disability ideology gaps among either citizens or candidates within parties. Interestingly, disabled Labour and UKIP candidates are more ideologically congruent with their non-disabled than their disabled supporters. With regard to public spending preferences, disabled citizens are again no more congruent with disabled than non-disabled candidates, except in the case of UKIP, although the coefficient is not statistically significant. These observations are more surprising than for left-right ideology, given that we found disability gaps in public spending attitudes of similar magnitudes among both citizens and candidates. 
On healthcare spending, disabled candidates of the Liberal Democrats and Green Party are more proximate to disabled party supporters than are non-disabled candidates. The coefficient for UKIP points in this direction as well but is not statistically significant. On the $0-1$ congruence scale, disabled Liberal Democrat supporters are 0.03 points closer to disabled than non-disabled candidates of their party. For the Greens, this congruence gap is 0.02 scale points. Together with the findings of disability gaps in NHS spending preferences, this result suggests that disabled candidates are indeed better at representing disabled citizens in the healthcare domain - at least in some parties. Meanwhile, disabled candidates are not more congruent with disabled party supporters than non-disabled candidates on income distribution in any of the parties. This is roughly in line with the earlier finding that disability does not have a statistically significant effect on candidate preferences on this issue.

\section{Conclusion}

Disabled people constitute an important minority group across all societies, in some cases even the largest (Nario-Redmond 2020). There is no doubt that this group is extremely diverse, and the barriers a person encounters depend on their type of impairment, their intersecting characteristics and identities, and their cultural, institutional and socio-economic context. Despite these differences, many disabled people have common experiences that are not shared by non-disabled people, leading to distinct political preferences and priorities, as this study has confirmed in the UK context (cf. Gastil 2000; Mattila et al. 2017; Schur and Adya 2013). This raises the question of whether comparable disability gaps also exist in the political preferences of political elites, and whether disabled citizens are as a result better represented by disabled politicians.

As the first to address the longstanding debate on the link between descriptive and substantive political representation within the unexplored context of disability, this study analysed survey data from citizens and candidates in the 2015 British general election. It approached the question from two perspectives that have previously been employed separately in research on group representation: (1) are there comparable disability preference gaps among citizens and elites and (2) are disabled elites more congruent with the preferences of disabled citizens?

The findings showed that disabled citizens clearly differ from non-disabled citizens by being more left wing and more supportive of public spending, income redistribution and healthcare spending. One might expect that by voting for parties that share these positions they can have their views represented. Yet, the preference differences persist even among supporters of the same parties. This study showed for the first time that similar disability gaps also exist among candidates: they express stronger support for public spending in general, and healthcare spending in particular, even compared to non-disabled candidates in their own parties. These findings suggest that having more disabled representatives in parliament will likely benefit the interests of disabled voters.

Although not all impairment types require medical attention, access to public healthcare is arguably a particularly important issue for the disability community (WHO 2018), and research from the United States suggests that disabled citizens assign higher priority to it than nondisabled citizens (Gastil 2000; Schur and Adya 2013). It might thus not come as a surprise that disability gaps exist especially on this issue. Similarly, research has shown there are intraparty gender gaps in particular on issues related to women's interests (Campbell, Childs and Lovenduski 2010; Lovenduski and Norris 2003; Wängnerud 2000). This finding raises important questions for future studies. For instance, what are the origins of shared preferences among disabled citizens and elites in different policy domains? Support for healthcare spending might arise out of self-interest, whereas the left-wing views and support for redistribution among disabled citizens may point to effects of disability on people's deeper value orientations, which in turn influence specific policy positions (cf. Huddy, Cassese and Lizotte 2008). Further research should explore these causal mechanisms, including analyses of more disability-specific issues. 
As part of this inquiry, scholars should ask how the preferences of disabled citizens are distinct from those of non-disabled citizens who experience marginalization. While I showed that the disability effects on preferences are robust to controlling for education and income, in-depth studies of the mediating factors may reveal additional insights. In this context, research should also examine the role of different impairment types in citizen and elite preferences, as they can imply very different barriers and experiences. This will further help determine whether we should consider disabled people a distinct social group for the purposes of political representation. This will also require impairment-specific data for political elites, which does not currently exist.

Beyond the study's novel insights into disability, preferences and representation, another key contribution is its twofold approach to the descriptive-substantive representation link. While we observed clear parallels in the effects of disability on the preferences of citizens and candidates, we also found that this does not necessarily result in higher preference congruence between disabled candidates and citizens: this was only the case for a few parties on the healthcare spending dimension. These divergent conclusions are most likely due to overall differences in the locations of citizens and candidates on the preference dimensions. This observation has parallels to Lax and Phillips' (2012) conclusion that public opinion and policy moving in the same direction is not necessarily associated with closer opinion-policy congruence. It draws attention to the fact that the measures we use to study social group representation have strong implications for our conclusions. The distinction between preference gaps and congruence gaps should thus be added to existing discussions of how to conceptualize and measure representation (for example, Golder and Stramski 2010; Lupu and Warner 2020).

This discussion will involve normative and theoretical considerations as well as empirical investigations, for instance into how different citizen-elite linkages influence the reflection of group preferences in policy and outcomes as well as citizens' political attitudes and behaviour. Disabled citizens are less likely to turn out in elections, even though their political interest is just as high when accounting for differences in resources (Reher 2020). Parties may be able to mobilize support among this sizeable group of voters by increasing the number of disabled politicians (cf. Banducci, Donovan and Karp 2004), who - as this study revealed - may offer policy positions that better reflect their interest with respect to some issues, most importantly healthcare. Given that voters base their vote choice particularly on the issues that are most salient to them (cf. Fournier et al. 2003), nominating disabled candidates might help parties gain additional support among disabled voters who care about healthcare and other public services.

However, this strategy might be more viable in PR systems, where disabled candidates have more opportunities to appeal specifically to disabled voters. Indeed, we would expect the preferences of disabled citizens and elites to be more aligned in these systems than in majoritarian systems like the UK. Future research should thus examine to what extent the arguments and findings of this study apply to other contexts. Besides the electoral system, other potential sources of crossnational variation in the disability-representation link are the number and visibility of disabled politicians as well as the degree of ableism in society, since the risk of being seen as 'tokens' or stigmatized might motivate disabled candidates to hide or normalize their disability. Crucially, taking this work forward will require collecting new data on the disability status of political elites outside the UK and on disability-related aspects of institutions, social structures and culture.

Acknowledgements. This research has greatly benefitted from feedback received at the ECPR Joint Sessions in Nicosia, the EPSA Meeting in Vienna, the Max Weber June Conference at the EUI, and the workshop 'Theoretical and Methodological Innovations in Comparative Politics' at the Cologne Center for Comparative Politics in 2018; the Departmental Seminar at Lancaster University, the Comparative Agendas Project Meeting in Budapest, and the APSA Annual Meeting in Boston in 2019; as well as the PSA PolMeth Conference in Manchester in 2020. I would like to thank the discussants and participants at these events as well as the three reviewers for their detailed and very helpful comments.

Data availability statement. Replication files for this article can be found in Harvard Dataverse at: https://doi.org/10.7910/ DVN/QPQUW5.

Supplementary material. Online appendices are available at https://doi.org/10.1017/S0007123420000733. 


\section{References}

Banducci SA, Donovan T and Karp JA (2004) Minority representation, empowerment, and participation. Journal of Politics 66(2), 534-556.

Belchior AM (2010) Ideological congruence among European political parties. Journal of Legislative Studies 16(1), $121-142$.

Bernardi L (2020) Depression and political predispositions: almost blue? Party Politics. doi: 10.1177/1354068820930391.

Boas TC and Smith AE (2019) Looks like me, thinks like me: descriptive representation and opinion congruence in Brazil. Latin American Research Review 54(2), 310-328.

Campbell R, Childs S and Lovenduski J (2010) Do women need women representatives? British Journal of Political Science 40(1), 171-194.

Charlton JI (1998) Nothing About Us Without Us: Disability Oppression and Empowerment. Berkeley and Los Angeles: University of California Press.

Clayton A et al. (2019) In whose interest? Gender and mass-elite priority congruence in Sub-Saharan Africa. Comparative Political Studies 52(1), 69-101.

Coffé H (2018) MPs' representational focus in MMP systems. A comparison between Germany and New Zealand. Representation 54(4), 367-389.

Collignon S and Rüdig W (2020) Harassment and intimidation of parliamentary candidates in the United Kingdom. The Political Quarterly 91(2), 422-429.

Cowley P (2013) Why not ask the audience? Understanding the public's representational priorities. British Politics 8(2), 138-163.

Crisp BF et al. (2016) The role of rules in representation: group membership and electoral incentives. British Journal of Political Science 48, 47-67.

Department for Work \& Pensions (DWP) (2020) Family Resources Survey 2018/19. Available from https://www.gov.uk/ government/statistics/family-resources-survey-financial-year-201819 (accessed 28 May 2020).

Dingler SC, Kroeber C and Fortin-Rittberger J (2019) Do parliaments underrepresent women's policy preferences? Exploring gender equality in policy congruence in 21 European democracies. Journal of European Public Policy 26(2), 302-321.

Durose C et al. (2011) Pathway to Politics. Equality and Human Rights Commission Research Report No. 65.

Emerson E, Vick B, Graham H, Hatton C, Llewellyn G, Madden R, Rechel B and Robertson J (2012). Disablement and Health. In Watson N, Roulstone A and Thomas C (eds), Routledge Handbook of Disability Studies. Abingdon: Routledge, pp. 253-270.

Evans E and Reher S (2020) Disability and political representation: analysing barriers to elected office in the UK. International Political Science Review. doi: 10.1177/0192512120947458

Fieldhouse E et al. (2015) British Election Study Internet Panel Wave 6. doi: 10.15127/1.293723.

Fournier P et al. (2003) Issue importance and performance voting. Political Behavior 25(1), 51-67.

Gastil J (2000) The political beliefs and orientations of people with disabilities. Social Science Quarterly 81, 588-603.

Giger N, Rosset J and Bernauer J (2012) The poor political representation of the poor in a comparative perspective. Representation 48(1), 47-61.

Golder M and Stramski J (2010) Ideological congruence and electoral institutions. American Journal of Political Science 54 (1), 90-106.

Griffin JD and Newman B (2007) The unequal representation of Latinos and Whites. Journal of Politics 69(4), 1032-1046.

Griffin JD, Newman B and Wolbrecht C (2012) A gender gap in policy representation in the U.S. Congress? Legislative Studies Quarterly 37(1), 35-66.

Home Office (2019) Hate Crime, England and Wales, 2018/19. Available from www.gov.uk/government/statistics/hate-crimeengland-and-wales-2018-to-2019 (accessed 28 May 2020).

Huber JD and Powell GB Jr (1994) Congruence between citizens and policymakers in two visions of liberal democracy. World Politics 46, 291-326.

Huddy L, Cassese E and Lizotte M-K (2008) Gender, public opinion, and political reasoning. In Wolbrecht C, Beckwith K and Baldez L (eds), Political Women and American Democracy. Cambridge: Cambridge University Press, pp. 31-49.

Inclusion London (2020). DDPO directory. Available from http://www.inclusionlondon.org.uk/directory/ (accessed 28 May 2020).

Kanter RM (1977) Some effects of proportions on group life. American Journal of Sociology 82(5), 965-990.

Keen R (2015). General Election 2015: candidates in numbers. House of Commons Library. Available from https://commonslibrary.parliament.uk/general-election-2015-candidates-in-numbers/ (accessed 28 May 2020).

Lau RR and Heldman C (2009) Self-interest, symbolic attitudes, and support for public policy: a multilevel analysis. Political Psychology 30(4), 513-537.

Lax JR and Phillips JH (2012) The democratic deficit in the states. American Journal of Political Science 56(1), 148-166.

Lloren A, Rosset J and Wüest R (2015) Descriptive and substantive representation of poor citizens in Switzerland. Swiss Political Science Review 21(2), 254-260.

Lovenduski J and Norris P (2003) Westminster women: the politics of presence. Political Studies 51, 84-102. 
Lupu N and Warner Z (2017) Mass-elite congruence and representation in Argentina. In Joignant A, Morales M and Fuentes C (eds), Malaise in Representation in Latin American Countries. New York: Palgrave Macmillan, pp. $281-302$.

Lupu N and Warner Z (2020) Affluence and congruence: unequal representation around the world. Journal of Politics (forthcoming).

Mansbridge J (1999) Should Blacks represent Blacks and women represent women? A contingent 'yes'. Journal of Politics 61 (3), 628-657.

Mattila M et al. (2017) Health and Political Engagement. Oxford: Routledge.

McColl MA, Jarzynowska A and Shortt SED (2010). Unmet health care needs of people with disabilities: population level evidence. Disability \& Society 25(2), 205-218.

Nario-Redmond MR (2010) Cultural stereotypes of disabled and non-disabled men and women: consensus for global category representations and diagnostic domains. British Journal of Social Psychology 49, 471-488.

Nario-Redmond MR (2020) Ableism: The Causes and Consequences of Disability Prejudice. Hoboken, NJ: Wiley.

Norris P and Lovenduski J (1995) Political Recruitment, Gender, Race and Class in the British Parliament. Cambridge: Cambridge University Press.

Office of National Statistics (ONS) (2019a) Disability and Education, UK: 2019. Available from http://www.ons.gov.uk/peoplepopulationandcommunity/healthandsocialcare/disability/bulletibu/disabilityandeducationuk/2019 (accessed 28 May 2020).

Office of National Statistics (ONS) (2019b) Disability Pay Gaps in the UK: 2018. Available from http://www.ons.gov.uk/peoplepopulationandcommunity/healthandsocialcare/disability/articles/disabilitypaygapsintheuk/2018\#half-of-disabled-people-aged-16-to-64-years-were-employed (accessed 28 May 2020).

Oliver M (1996) Understanding Disability: From Theory to Practice. Basingstoke: Macmillan.

Phillips A (1995) The Politics of Presence. Oxford: Clarendon Press.

Pitkin HF (1967) The Concept of Representation. Berkeley: University of California Press.

Rapeli L, Mattila M and Papageorgiou A (2020) Breaking a habit: the impact of health on turnout and party choice. Party Politics 26(2), 133-142.

Reher S (2020), “Replication Data for: Do Disabled Candidates Represent Disabled Citizens?”, https://doi.org/10.7910/DVN/ QPQUW5, Harvard Dataverse, V1, UNF:6:QSvAxnCJJhV7t9VEIzDNbQ== [fileUNF]

Reher S (2020) Mind this gap, too: the roles of resources and representation in the political orientations of citizens with disabilities. Political Behavior 42, 791-818.

Rohmer O and Louvet E (2018) Implicit stereotyping against people with disability. Group Processes \& Intergroup Relations 21(1), 127-140.

Sakellariou D and Rotarou ES (2017) Access to healthcare for men and women with disabilities in the UK: secondary analysis of cross-sectional data. BMJ Open 7(e016614), 1-9.

Schakel W and Hakhverdian A (2018) Ideological congruence and socio-economic Inequality. European Political Science Review 10(3), 441-465.

Schur L and Adya M (2013) Sidelined or Mainstreamed? Political Participation and Attitudes of People with Disabilities in the United States. Social Science Quarterly 94(3), 811-839.

Sobolewska M (2013) Party strategies and the descriptive representation of ethnic minorities: the 2010 British general election. West European Politics 36(3), 615-633.

Sobolewska M, McKee R and Campbell R (2018) Explaining motivation to represent: how does descriptive representation lead to substantive representation of racial and ethnic minorities? West European Politics 41(6), 1237-1261.

Tremblay M (2003) Women's representational role in Australia and Canada: the impact of political context. Australian Journal of Political Science 38(2), 215-238.

UN General Assembly (2007) Convention on the Rights of Persons with Disabilities: Resolution/adopted by the General Assembly, 24 January 2007, A/RES/61/106.

Van Heerde-Hudson J and Campbell R (2015) Parliamentary UK Dataset (v. 1). Available from http://www.parliamentarycandidates.org.

Wängnerud L (2000) Testing the politics of presence: women's representation in the Swedish Riksdag. Scandinavian Political Studies 23(1), 67.

World Health Organization (WHO) (2011) World Report on Disability. World Health Organization and World Bank. Available from http://www.who.int/disabilities/world_report/2011/report/en/ (accessed 28 May 2020).

World Health Organization (WHO) (2018) Disability and Health. World Health Organization. Available from www.who. int/news-room/fact-sheets/detail/disability-and-health (accessed 28 May 2020).

Wüest R and Pontusson J (2018) The Representation of Social Classes in European Parliaments. Paper presented at the Annual Conference of the European Political Science Association, Vienna, 21-23 June.

Cite this article: Reher S (2022). Do Disabled Candidates Represent Disabled Citizens? British Journal of Political Science 52, 520-534. https://doi.org/10.1017/S0007123420000733 